\title{
Differentiating Optimists from Pessimists in the Prediction of Emotional Intelligence, Happiness, and Life Satisfaction: A Latent Profile Analysis
}

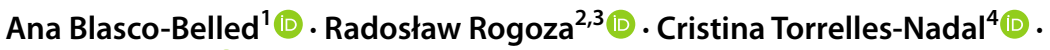 \\ Carles Alsinet ${ }^{4}$ (D)
}

Accepted: 31 January 2022 / Published online: 23 February 2022

(C) The Author(s) 2022

\begin{abstract}
What are the differences between optimists and pessimists? The aim of this study is to analyze the differences reported by optimists and pessimists in terms of three psychological variables: emotional intelligence (EI), happiness, and life satisfaction. To answer this question, we examined the extent to which a combination of different levels of optimism and pessimism can differently predict EI, happiness, and life satisfaction in two independent samples (891 adults, 494 adolescents). To do that, we introduced a person-centered approach, which offers several advantages in the study of optimism over the extended, predominant variable-centered approach. Then, using a latent profile analysis, we identified three groups of individuals with a similar optimism-pessimism configuration: optimists, ambivalents, and pessimists. The results obtained supported our hypothesis that optimists report higher EI, happiness, and life satisfaction levels than those reported by pessimists. Low levels of optimism, rather than high levels of pessimism, distinguish optimistic from non-optimistic people in the prediction of external outcomes. Our results suggest that optimism and pessimism can be viewed as separate yet correlated traits that can be grouped together to explain individual affective and cognitive differences, which encourage the refinement of strategies and interventions used in psychology practice.
\end{abstract}

Keywords Optimism · Pessimism · Emotional intelligence $\cdot$ Happiness $\cdot$ Life satisfaction · Latent profile analysis

\section{Introduction}

Although the popular expression of "seeing the glass half full or half empty" might be recognized as a popular cliché to refer to optimists and pessimists outside of the scientific community, little is known about what makes people see the same glass in a different manner. To date, research has differentiated optimists from pessimists in several dynamics. Behaviorally, optimists are more perseverant of goal accomplishments

Ana Blasco-Belled

ana.blasco@udg.edu

Extended author information available on the last page of the article 
by means of active problem-solving strategies, and they enjoy a higher probability of success. Cognitively, optimists picture a brighter future, which is likely to be reached through plan-guided behavior. Emotionally, optimists feel confident when facing adversity and tend to make use of their affective resources when dealing with uncertainty and goal unattainability (Carver et al., 2010). Notwithstanding, little is known about the combination of different levels of optimism and pessimism that set these two profiles apart. Therefore, the aim of this study is to provide empirical arguments to strengthen the question of why people might see the same glass in different ways by identifying individual similarities and differences between optimists and pessimists.

\subsection{Optimism, Pessimism, and Outcome-related Differences}

From the traditional perspective, optimism is a trait defined as an individual's generalized expectation of the occurrence of positive future events (Carver et al., 2010). Optimism has been positively associated with emotional, physical, and mental health (Bouchard et al., 2017; Gallagher et al., 2019) and negatively associated with anxiety (Boman \& Yates, 2001) and depression (Shapira \& Mongrain, 2010). On the other hand, pessimism has been associated with lower psychological well-being, health-damaging behaviors, and social withdrawal (Carver et al., 2003), higher risk of suffering depression and obsessive-compulsive symptoms (van der Velden et al., 2007). Unlike optimism, pessimism yields people to expect darker scenarios, to be doubtful and insecure about their chances to reach a goal, and to persevere less and thus be less likely to succeed (Carver et al., 2010; Nes \& Segerstrom, 2006). While optimism is characterized by the flexible use of adaptive coping strategies (e.g., dealing with adverse situations), pessimism is characterized by the use of disengagement strategies (e.g., escaping from the stressor) that hinder goal accomplishment (Nes \& Segerstrom, 2006), which was conceptualized as a maladaptive strategy related to negative outcomes (Prati \& Pietrantoni, 2009).

The assessment of optimism has been surrounded by debates about its dimensionality. Although the scale to assess optimism was designed to measure it as a one-dimensional construct (Scheier \& Carver, 1985), other authors have advocated a bidimensional structure wherein optimism and pessimism are better accounted as separate factors (Deptula et al., 2021; Herzberg et al., 2006; Hinz et al., 2017; Jovanović \& Gavrilov-Jerković, 2013), even in adolescent samples (Creed et al., 2002; Tejada-Gallardo et al., 2020). Arguing that measuring optimism-pessimism as a continuum may miss important information, Marshall et al. (1992) demonstrated that optimism and pessimism are two different factors in terms of structure (e.g., a two-factor structure showed better fit than a one-factor structure) and relationships with personality and affect (e.g., optimism was related to extraversion and positive affect, whereas pessimism was related to neuroticism, depression and negative affect).

In view of the above-mentioned, and following the call of Carver et al., (2010) for more research into the dimensionality of optimism, applying an alternative perspective to measure it can provide novel insights about the structure of optimism. Supported by the notion that changes in personality traits and life experiences are reciprocal and continuously influence each other (Wrzus \& Roberts, 2017), scholars have challenged the trait stability of optimism ( $\mathrm{Li}$ et al., 2019). In the same way that this finding broadened the understanding of optimism beyond the traditional trait view, we propose that research in the field can also 
benefit from embracing a person-centered approach in which optimism and pessimism are seen as the result of an interplay of characteristics.

\subsection{Optimism or Optimists? From a Variable-centered to a Person-centered Approach}

A relevant aspect of the aforementioned studies is that their results were obtained following a variable-centered approach, based on the premise that optimism has a dimensional structure (Eichner et al., 2014). The focus of those studies was on describing associations between variables (i.e., predictors explaining variance in outcomes; Eye \& Bogat, 2006; Muthén \& Muthén, 2000). Despite the results obtained from this approach alluded to optimism (and pessimism) as a general construct rather than personal characteristics, researchers and laypeople interchangeably refer to optimists (and pessimists) when describing others in real life settings. This might reflect inaccuracy in interpretation of the results, since studies from the variable-centered approach seem unsuited to infer such attributions.

By contrast, the person-centered approach focuses on describing intraindividual differences between groups (Lubke \& Muthén, 2005) as it assumes that the sample might be composed of different subgroups of individuals with a distinct set of characteristics, which can also serve to assess the dimensionality of psychological constructs (Morin et al., 2017). Provided that the group studied is non-homogeneous and the variables are not connected to each other in the same way for all people, the potential of the person-centered approach is in dividing the sample into profiles that share a similar optimism-pessimism configuration (Eye \& Bogat, 2006; Muthén \& Muthén, 2000). As a result, the person-centered approach groups people (e.g., optimists) instead of variables (e.g., optimism). This approach was recently applied to peer optimism in a longitudinal study (Deptula et al., 2021), and although the sample (children) and the measurement (peer optimism) were different from our study, the results suggested that the person-centered approach can be useful in this line of inquiry.

The introduction of this approach in the study of optimism offers several advantages that could not otherwise be obtained using a variable-centered approach. For instance, we can categorize individuals, revealing the proportions of people in each group in an empirical world. In addition, we can examine the complex interactions between optimism and pessimism by identifying different profiles, rather than by probing the interaction effect between optimism and pessimism on arbitrary guidelines; for example, individuals 1 standard deviation $(S D)$ above the mean of optimism and $1 S D$ below the mean of pessimism as a group.

Assuming that variations in optimism are one of degree rather than kind (Eichner et al., 2014), our primary concern is not to find out how many types of optimists or non-optimists exist, but rather to examine the outcomes that different combinations of optimism-pessimism levels can produce. This allows referring to optimists and pessimists more accurately through person-centered analyses. Since variable- and person-centered approaches address different research questions and are complementary (Morin et al., 2017), they may shed light on the study of optimism from distinct and insightful perspectives. 


\subsection{Selection of Variables to Identify Different Profiles}

To explore the extent to which optimists and pessimists differ in the prediction of external variables, we examined different correlates, such as emotional intelligence (EI) and two indicators of subjective well-being (i.e., life satisfaction and happiness). EI refers to the capacity to process emotion-related information (Salovey \& Mayer, 1990). As components of subjective well-being, life satisfaction captures individuals' cognitive evaluations of their life circumstances, whereas happiness captures individuals' emotional experiences (Diener et al., 1999). Although happiness can entail different definitions depending on the cultural context, it generally involves a preponderance of positive over negative emotional states (Bradburn, 1969). These three variables have been largely related to optimism in the literature (see Segerstrom et al., 2017) and can contribute to differentiate between optimistic and pessimistic individuals. With regard to the components of EI, optimism was related positively to emotional clarity and emotional repair, while pessimism was related positively to emotional attention and negatively to emotional repair (Extremera et al., 2007; Tejada-Gallardo et al., 2020). Optimism is a strong predictor of happiness and life satisfaction (Alarcon et al., 2013; Chang et al., 2020; Daukantaitė \& Zukauskiene, 2012), although the prospective effects on these outcomes seem to be weaker (Jovanović et al., 2021).

\subsection{The Current Study}

The primary goal of the current study is to investigate the extent to which optimists differ from pessimists in terms of EI, happiness, and life satisfaction. To that end, we aim to identify several profiles of individuals sharing similar characteristics based on a combination of different levels of optimism and pessimism. To provide additional validation to our hypothesis, we analyzed the profiles in a sample of adults and adolescents to test whether the distribution can be replicated in different populations. This field of research has accumulated great knowledge over the past decades. However, to our concern, no study has addressed the question of how optimistic and pessimistic people can be distinguished on the basis of a combination of these traits, and there is a lack of studies explicitly focusing on pessimists (Carver et al., 2010). Since optimists use more adaptive coping and have higher positive expectancies than pessimists as a result of past experiences (Scheier \& Carver, 1985), we hypothesize that optimists will report higher EI, happiness, and life satisfaction levels than those reported by pessimists.

\section{Method}

\subsection{Participants and Procedure}

Data were obtained from two separate samples. The first sample comprised 891 undergraduates from the University of Lleida, Spain $\left(73.3 \%\right.$ female; $\left.M_{\text {age }}=21.61 ; S D=4.18\right)$ who participated voluntarily in a project consisting in the identification and promotion of positive traits and did not receive any compensation. The second sample comprised 494 adolescents $\left(52.7 \%\right.$ female; $\left.M_{\text {age }}=15.31 ; S D=0.54\right)$ from two high schools who participated in the same project, which was adapted to this population. All participants were provided with access to an online platform to complete a survey including all the measures. The research conditions for obtaining the data from adults and adolescents were the same. They 
completed the questions in around 15 min and obtained an individualized report with their results at the end, which was subsequently explained by a psychologist to allow them to understand the role of these traits in the promotion of well-being. We provided an explanation of the study's goals in the survey, including the terms of confidentiality and anonymity. We also extensively informed the participants regarding the procedure and purpose of the project, and they signed an informed consent form prior to enrollment in the program. For adolescents, the consent was obtained from their parents or legal tutor. Only those who completed the whole protocol were included in the study.

\subsection{Measures}

The Life Orientation Test-Revised (LOT-R; Scheier et al., 1994; Spanish version by Ferrando et al., 2002) is a scale composed of six items (three positively and three negatively worded) evaluating whether people expect good or bad outcomes in life using a 7-point Likert scale $(0=$ strongly disagree to $7=$ strongly agree $)$. Four additional filler items are included but they are not subjected to analysis. The reliability estimate for optimism and pessimism was $\alpha=0.71$ and $\alpha=0.60$, respectively ${ }^{1}$ for adults, and $\alpha=0.71$ and $\alpha=0.57$, respectively for adolescents. A sample item is, "In uncertain times, I usually expect the best."

The Satisfaction with Life Scale (SWLS; Diener et al., 1985; Spanish version by Vázquez et al., 2013) is a five-item questionnaire that evaluates the degree of satisfaction with life as a whole. Participants are asked to rate their satisfaction with life on a 7-point Likert scale $(1=$ strongly disagree to $7=$ strongly agree). The reliability estimate was $\alpha=0.80$ for adults and $\alpha=0.82$ for adolescents. A sample item is, "So far I have gotten the important things I want in life."

The Subjective Happiness Scale (SHS; Lyubomirsky \& Lepper, 1999; Spanish version by Extremera \& Fernández-Berrocal, 2014) is a four-item (one reversed) survey in which participants rate the extent to which they are in accordance with happiness statements on a 7-point Likert scale, considering the definition of happiness from the respondent's perspective. The internal consistency was $\alpha=0.74$ for adults and $\alpha=0.60$ for adolescents. A sample item is, "Compared with most of my peers, I consider myself..." (e.g., $1=$ less happy to $7=$ more happy).

The Trait Meta-Mood Scale (TMMS-24; Salovey et al., 1995; Spanish version by Fernández-Berrocal, Extremera, \& Ramos, 2004) comprises 24 items assessing perceived EI and provides scores on three dimensions: emotional attention (attending ones' and others' affective responses), emotional clarity (identifying and understanding those emotional patterns), and emotional repair (being able to regulate ones' and others' emotions in order to cope with situational demands). It uses a 5-point Likert scale (1=strongly disagree to $5=$ strongly agree $)$. The internal reliability was $\alpha_{\text {attention }}=0.89 ; \alpha_{\text {clarity }}=0.88$; and $\alpha_{\text {repair }}=0.85$ in adults, and $\alpha_{\text {attention }}=0.87 ; \alpha_{\text {clarity }}=0.88$; and $\alpha_{\text {repair }}=0.83$ in adolescents. A sample item (for emotional clarity) is, "I am usually very clear about my feelings."

\footnotetext{
1 Previous studies also found low reliabilities in pessimism (Abdullah et al., 2018; Armbruster, Pieper, Klotsche \& Hoyer, 2015). Given the low number of items, alpha's reliability might be artificially low (see e.g., Sijtsma, 2009). We also tested the reliability of the one-factor model and $\alpha$ was .71 in adults and .61 in adolescents.
} 


\subsection{Data Analysis}

First, we tested whether each measure is a structurally valid instrument in each of the two samples using confirmatory factor analyses. We analyzed the following measurement models: (1) the LOT-R, which comprises two correlated factors measuring optimism and pessimism, each loaded by three respective items; the (2) one-factor SWLS; (3) the one-factor SHS; and (4) the TMMS-24, in which 8 items are loaded on each specific factor of emotional attention, clarity, and repair (factor loadings are reported in supplementary materials). To evaluate the fit of these measurement models, we followed the standard criteria of Comparative Fit Index (CF) and Tucker-Lewis Index (TLI) $>0.90$ and Root Mean Square Error of Approximation (RMSEA) $<0.08$ (Byrne, 1994). We used the robust maximum likelihood estimation for all models tested. After the verification of the measurement models, we extracted the latent means (i.e., factor scores of each individual) because they have been found to be superior to summated scores, as a result of the control of the shared variance and measurement error (Kline, 2013).

To assess whether people can be characterized by a combination of different levels in optimism and pessimism, we followed the three-step procedure for latent class predictor variables (Asparouhov \& Muthén, 2014). This method allows testing how people differ in being optimistic and pessimistic and how these differences predict the association with external outcomes (i.e., distal outcomes), such as EI, happiness, and life satisfaction.

In the first step, we used latent profile analysis (LPA), a variant of latent class analysis for continuous variables, to identify the smallest number of subgroups of individuals sharing similar characteristics (i.e., latent profiles) on the basis of a combination of the observed variables (i.e., indicators), such as optimism and pessimism. In other words, we analyzed whether it is possible to distinguish the profiles of people who differ in their combination of being optimistic and pessimistic. To determine how many profiles should be extracted, we evaluated the Akaike information criterion (AIC), Bayesian information criterion (BIC), and adjusted BIC (aBIC), the lowest value of which suggested the best-fitting number of classes (Li et al., 2019). In addition, we used the Lo-Mendell-Rubin likelihood ratio test (LMR), adjusted LMR (aLMR), and bootstrap likelihood ratio test (BLRT) to compare the models of the $k$ profile and $k-1$ profile. When comparing models (e.g., three-profile versus four-profile), the presence of significant $p$-values in the higher-class model (four-profile) indicates a preference to choose the model with one fewer class (threeprofile) (Nylund et al., 2007). In addition to these indicators, to select the most appropriate model, it is important for the classes of each latent profile model to be interpretable, with a considerable size, and its manifest allocation should be characterized by overall certainty (Wetzel et al., 2016).

In the second step, we estimated the measurement error for the most likely class variable $N$, which was used as a latent class indicator (specified as a nominal variable) in the following step. In the third and final step, we analyzed whether profile membership predicts differences in relation to distal outcomes to test our hypothesis that optimists report higher EI, happiness, and life satisfaction levels than those reported by pessimists. Associations with distal outcomes were explored as a function of linear regression with class-varying residual variances (Asparouhov \& Muthén, 2014). All analyses were performed in Mplus v.7.2 (Muthén \& Muthén, 1998-2012). The data and syntaxes necessary to replicate the study are available at Open Science Framework. 
Table 1 Model fit of the measurement models

\begin{tabular}{lllllll}
\hline & & $\chi_{(\mathrm{df})}^{2}$ & $p$ & CFI & TLI & RMSEA[90\%CI] \\
\hline Adults & & & & & & \\
& & & & & & \\
& Optimism & $812.608_{(15)}$ & $<.001$ & .971 & .946 & $.057[.036-.078]$ \\
& Life satisfaction & $1116.241_{(10)}$ & $<.001$ & .989 & .977 & $.053[.028-.081]$ \\
& Happiness & $671.384_{(6)}$ & $<.001$ & 1.000 & 1.002 & $.000[.000-.062]$ \\
& Emotional intelligence & & \\
& & $8560.295_{(276)}$ & $<.001$ & .901 & .888 & $.061[.058-.065]$ \\
& & & & & & \\
& Optimism & $355.214_{(15)}$ & $<.001$ & .935 & .877 & $.075[.048-.105]$ \\
& Life satisfaction & $711.255_{(10)}$ & $<.001$ & .998 & .997 & $.022[.000-.069]$ \\
& Happiness & $325.813_{(6)}$ & $<.001$ & 1.000 & 1.006 & $.000[.000-.081]$ \\
& Emotional intelligence ${ }^{\mathrm{b}}$ & $4978.038_{(276)}$ & $<.001$ & .903 & .891 & $.061[.056-.067]$ \\
\hline
\end{tabular}

$p$-values are significant at .05

${ }^{\mathrm{a}}$ Correlation between residuals were freed between items 1-2, 6-7, 12-13, and 12-factor 1 (emotional attention)

${ }^{\mathrm{b}}$ Correlation between residuals were freed between items $2-8,12-13$ and 22-23

\section{Results}

\subsection{Verification of the Underlying Factorial Structure of the Measures}

As an initial step, each measurement model was verified to extract the latent mean scores on which the LPA was based. Table 1 presents the model fit of the analyzed models.

All the models were well fitted to the data, confirming the hypothesized factorial structure of the measures. ${ }^{2}$ In order to achieve acceptable model fit, we added correlations between certain residuals in the model of EI as indicated by the inspection of the modification indices (see the syntax available at OSF). The latent means could, thus, be meaningfully used within the LPA. ${ }^{3}$

\subsection{Differentiation of Classes According to the Combination of Optimism and Pessimism}

In total, we tested five latent profile models differing in the number of classes (from two- to six-profile). For adults, according to the AIC and BIC, the six-profile model should be chosen as the best-fitted model (see Table 2). Nonetheless, the LMR test was non-significant for the five-profile model, indicating a preference to choose the model with one fewer class. Although the entropy values were moderate, they were similar across all the compared groups, suggesting that adults can be classified into profiles with certainty. The average latent class probabilities, which inform about the probability of being in a profile according to the pattern of scores on indicator variables, ranged

\footnotetext{
${ }^{2}$ We also tested the one-factor model of optimism and the fit indices were worse than the two-factor model $\left(\chi 2_{(\mathrm{df})}=812.608_{(15)}, \mathrm{p}<.001, \mathrm{CFI}=.820, \mathrm{TLI}=.701, \mathrm{RMSEA}[90 \% \mathrm{CI}]=.134[.115-.153]\right.$ for adults; $\chi_{(\mathrm{df})}=355.214_{(15)}, \mathrm{CFI}=.650, \mathrm{TLI}=.417, \mathrm{RMSEA}[90 \% \mathrm{CI}]=.164[.139-.190]$ for adolescents).

${ }^{3}$ Full scalar invariance was achieved for optimism and pessimism. See supplementary materials.
} 


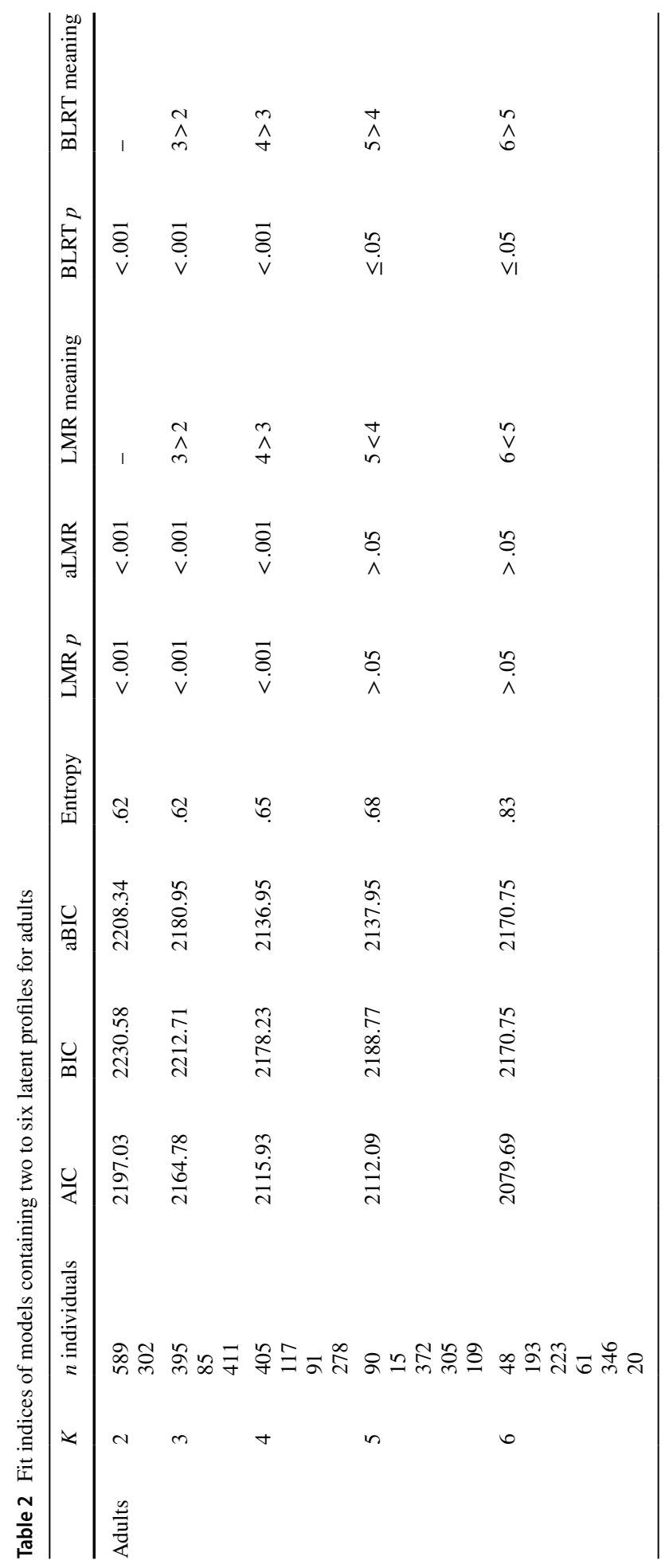



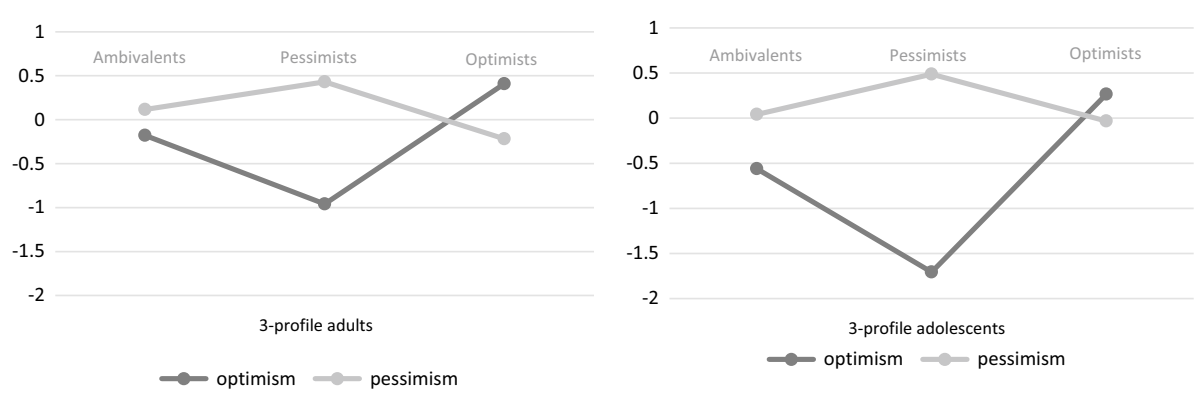

Fig. 1 Three-Profile Model in Adults (left) and Adolescents (right)

Table 3 Latent mean scores on optimism and pessimism across latent profiles for adults

\begin{tabular}{lllll}
\hline & Variables & Profile 1 Ambivalents & Profile 2 Pessimists & Profile 3 Optimists \\
\hline Adults & & $(n=395 ; 44.3 \%)$ & $(n=85 ; 9.6 \%)$ & $(n=411 ; 46.1 \%)$ \\
& Optimism & -.18 & -0.96 & .41 \\
& Pessimism & .12 & .43 & -.22 \\
\hline
\end{tabular}

from 0.75 (class 3) to 0.85 (class 2) for the four-profile model, suggesting good certainty of classification.

The replication results in adolescents indicated that the three-profile model should be selected (see supplementary materials for details). Figures 1 and S1 present the latent means of optimism and pessimism for the four- and three-profile models to clarify the distribution of classes. The three-profile models comprised a group of ambivalents (similar scores in optimism and pessimism, with values close to 0), optimists (higher scores in optimism than in pessimism), and pessimists (higher scores in pessimism than in optimism). Likewise, the four-profile models comprised a group of optimists, ambivalent-highs (similar scores in optimism and pessimism, with values above 0), pessimists, and ambivalentlows (similar scores in optimism and pessimism, but with lower scores than those of the ambivalent-highs). Given that ambivalent-highs and ambivalent-lows followed akin distributions, we considered the option of joining them. Based on the descriptives, the groups of ambivalents in the three-profile models comprised the two groups of ambivalent-highs and ambivalent-lows from the four-profile models in both samples. In fact, the sum of ambivalent-highs and ambivalent-lows in the four-profile model for adults resulted in the same number of participants as the class of ambivalents in the three-profile model $(n=395)$.

Given all of this, and for the sake of interpretation, we decided to select the three-profile model (for both samples). Although we acknowledge that several statistical indicators suggested a preference for the four-profile model for adults, the conceptual sense for result interpretation and the small differences between the profiles guided our decision that the three-profile model would be more informative. Table 3 shows the mean scores of optimism and pessimism across the three profiles for adults.

The three profiles were labeled as ambivalents (class 1), pessimists (class 2), and optimists (class 3). The first class, which accounted for $44.3 \%$ of adult participants, comprised people who were slightly pessimists and low optimists. The second class represented $9.6 \%$ of the adults and comprised people with high levels of pessimism and very low levels of 
Table 4 Mean scores across latent profiles on emotional intelligence, happiness and life satisfaction displayed by adults

\begin{tabular}{llllll}
\hline Outcome & $\begin{array}{l}\text { Profile 1 } \\
\text { Ambivalents } \\
\text { M (SE) }\end{array}$ & $\begin{array}{l}\text { Profile 2 Pessimists M } \\
\text { (SE) }\end{array}$ & $\begin{array}{l}\text { Profile 3 } \\
\text { Optimists M } \\
(\mathrm{SE})\end{array}$ & $\begin{array}{l}\text { Significant dif- } \\
\text { ferences between } \\
\text { profiles }\end{array}$ \\
\hline Adults & & & & & \\
& Emotional attention & $-.036(.03)$ & $-.071(.06)$ & $.056(.03)^{*}$ & $2=1<3$ \\
& Emotional clarity & $-.141(.04)^{* * *}$ & $-.679(.08)^{* * *}$ & $.326(.04)^{* * *}$ & $2<1<3$ \\
& Emotional repair & $-.308(.04)^{* * *}$ & $-.868(.09)^{* * *}$ & $.547(.04)^{* * *}$ & $2<1<3$ \\
& Happiness & $-.158(.04)^{* * *}$ & $-1.473(.09)^{* * *}$ & $.554(.03)^{* * *}$ & $2<1<3$ \\
& Life satisfaction & $-122(.05)^{* *}$ & $-1.420(.09)^{* * *}$ & $.507(.03)^{* * *}$ & $2<1<3$ \\
\hline
\end{tabular}

${ }^{*} p<.01 ; * * p<.005 ; * * * p<.001$

1 refers to " " $="$ the groups are not significantly different

optimism. The third class was the most numerous and represented $46.1 \%$ of the adults, characterized by higher levels of optimism than those of pessimism (with negative or close-to-zero scores).

\subsection{Prediction of Distal Outcomes}

Table 4 presents the mean scores for distal outcomes across each latent profile in adults.

Only the group of optimists showed positive associations with the predicted outcomes, while pessimists and ambivalents exhibited negative associations, with pessimists reporting more negative values. This supported our hypothesis. In the case of adults, pessimists had the highest associations with happiness and life satisfaction (negative), ambivalents had the highest associations with emotional repair (negative), and optimists had the highest associations with happiness and emotional repair. Among the three EI components, emotional attention was only significant for optimists. Emotional repair presented the highest mean scores, in either a positive or a negative way. These results suggest that optimism is related to more positive outcomes, with emotional attention as a discriminant predictor of non-optimistic people (i.e., pessimists and ambivalents). ${ }^{4}$

\section{Discussion}

Several academic debates continue to focus on the boundaries between optimists and pessimists. Since research advocates the dimensional latent structure of optimism, several endeavors have been made to increase the degree of optimism rather than turning pessimists into optimists (Eichner et al., 2014). Considering these findings, we investigated the extent to which differences in the degree of optimism/pessimism can be used for grouping people with a similar configuration. The introduction of a person-centered approach, a novelty in this field, showed that variations in the degree of optimism/pessimism revealed

\footnotetext{
${ }^{4}$ All the results for the adolescent sample are presented in the supplementary materials. The pattern of relationships was replicated and therefore the findings were consistent with those of the adult sample.
} 
differences in the prediction of EI, happiness, and life satisfaction. This allows us to provide some insights into how to refine strategies aimed at promoting optimism.

\subsection{Can We Identify Optimists and Pessimists?}

In general, the present findings have important implications that connect directly with the scientific discussion about the structure of optimism. In light of our results, optimism and pessimism can be viewed as separate yet correlated traits that can be grouped together to explain individual affective and cognitive differences. Although some researchers advocate for a unidimensional continuum for the sake of "simplicity" (Segerstrom et al., 2017, p.197), a two-dimensional structure has been supported by the literature (Deptula et al., 2021; Herzberg et al., 2006; Hinz et al., 2017; Jovanović \& Gavrilov-Jerković, 2013).

Our study showed that it is possible to describe different profiles with a similar combination of optimism/pessimism. To reinforce our findings, we replicated the analysis in two independent samples. This does not negate the fact that optimism has a latent structure or that people differ in the degree of this trait; our analysis, however, encourages the consideration of the possibility of categorizing individuals on the basis of a complex interaction between optimism and pessimism. Because our main interest was to examine the potential differences of each profile in relation to certain outcomes, the present findings might bridge with the valuable literature from the variable-centered approach.

Three distinct profiles were described across the two samples: optimists, ambivalents, and pessimists. Supporting our hypothesis, optimists showed greater EI, happiness, and life satisfaction levels than those shown by pessimists. More specifically, happiness, emotional repair, and life satisfaction were the outcomes with the highest (and lowest) scores for optimists (and pessimists). A more detailed discussion regarding the main outcomes is provided in the remaining of the section.

\subsection{Optimists Predict Different Outcomes than Pessimists}

Studies investigating several paths of difference between optimists and pessimists have indicated that those with more positive expectancies are less emotionally vulnerable and cope better with adversity (Barnett \& Martinez, 2015; Chang et al., 2020). In our study, individuals in the optimistic profile reported higher emotional repair, which might explain the tendency of optimists to accept reality, reframe uncontrollable situations (i.e., viewing the situation in the best possible light; Aspinwall et al., 2001), and use flexible, adaptive coping strategies (e.g., dealing with adverse situations; Nes \& Segerstrom, 2006).

Emotional attention seemed to be a discriminant outcome between optimists and nonoptimists (e.g., ambivalents and pessimists). The significant negative relationship with emotional attention in the group of ambivalent adolescents (characterized by very low levels of optimism) suggests that low levels in this trait are associated with a worse performance of this EI component. A previous study highlighted the role of emotional attention in predicting less happiness and life satisfaction, seemingly due to the sensitivity of individuals to perceive more distress (Blasco-Belled et al., 2020). We presume that optimists may display a more appropriate level of emotional attention that favors their regulatory strategies aimed at reducing stressors. Overall, holding a positive outlook of life might facilitate the envisioning of potential future difficulties, affording the possibility of planning behavior and choosing the most appropriate course of action (Taylor \& Schneider, 1989). 
We found that being optimistic, rather than pessimistic, is associated with greater happiness and life satisfaction. This is in line with previous literature linking optimism to more adaptive outcomes, such as better well-being and mental health (Bouchard et al., 2017; Gallagher et al., 2019). In a similar vein, Joshanloo et al. (2017) showed that optimism moderates the relationship between the fragility of happiness (i.e., the belief that happiness is fragile and temporary) and happiness, but only in individuals with low levels of optimism. This suggests that a lack of positive future expectancies can reduce subjective well-being.

\subsection{General Implications}

Conceptualizing optimism and pessimism separately may have two main implications in the general field. First, this separation might prove helpful to understand the distinct patterns of behavior, specifically future thinking, across cultures; in some countries, being pessimistic promotes coping strategies, whereas in others it relates to effective problem resolution (Baumeister et al., 2016). Second, it may refine the direction that optimismbased strategies should follow. It seems that what makes the glass half full is the presence of moderate to high levels of optimism, rather than the lack of pessimism. Hence, increasing people's levels of optimism, rather than preventing pessimism, should be a target of psychological interventions. Navigating from lower to upper levels of optimism seems to be more tenable than preventing people from being pessimistic (Eichner et al., 2014). We briefly propose some evidence-based caveats that could be useful for practitioners.

Developing alternative, self-enhancing explanations to (re)interpret life events can be effective to increase the levels of optimism. To do that, cognitive reconstruction and positive imagery have proved useful in clinical and cognitive therapy (Eagleson et al., 2016; Wright et al., 2006). Optimism-based strategies for clinical and community samples typically include the recall of positive experiences and the maintenance of pleasure (i.e., savoring strategies) because they contribute to positive emotional regulation and happiness (Koydemir et al., 2020). This merits consideration because, insofar as low optimism is associated with higher attention to emotions, which thereafter seems to decrease well-being, engaging in a more optimistic outlook may also promote EI. Altogether, by understanding the distinguishing outcomes between optimists and pessimists, research can pave the way for sharpening the specific components to be addressed in psychological interventions.

\subsection{Limitaions and Future Directions}

Some limitations need to be acknowledged. This study was cross-sectional in nature and it was based on self-report measures. Hence, it would be useful to include non-standard instruments to assess behavioral assets in future research. The sample of adults was almost twice as big as that of adolescents and both groups reported different variances in the measures. These specificities may hinder the comparison of the results, and the high representativeness of the mean in the adolescent sample suggests that it may be a non-random sample. Although the two samples reported a similar configuration of profiles, the decision to select the three-profile model was based upon conceptual and statistical criteria, yet the group of pessimists in adolescents was very small. Therefore, the interpretation and generalization of the results should be made with caution. Also, the difference in age across the two samples may be small, and potential developmental differences may take place. 
Replicating the results in different cultures and with larger differences in age might be worth consideration in future studies.

Supplementary Information The online version contains supplementary material available at https://doi. org/10.1007/s10902-022-00507-4.

Acknowledgement The authors wish to thank Claudia Tejada-Gallardo for her help and assistance in the analysis of the results.

Authors' contribution Conceptualization: Ana Blasco-Belled; Methodology: Ana Blasco-Belled and Radosław Rogoza; Writing - original draft preparation: Ana Blasco-Belled; Writing - review and editing: Radosław Rogoza and Cristina Torrelles-Nadal; Resources: Carles Alsinet; Supervision: Carles Alsinet.

Funding Open Access funding provided thanks to the CRUE-CSIC agreement with Springer Nature. This research has not been funded.

Availability of data and materials The data and syntaxes necessary to replicate the study are available at https://osf.io/d7wft/.

Code availability Mplus v.7.2 (Muthén \& Muthén, 1998-2012).

\section{Declarations}

Conflict of interest The authors have no conflicts of interest to disclose.

Open Access This article is licensed under a Creative Commons Attribution 4.0 International License, which permits use, sharing, adaptation, distribution and reproduction in any medium or format, as long as you give appropriate credit to the original author(s) and the source, provide a link to the Creative Commons licence, and indicate if changes were made. The images or other third party material in this article are included in the article's Creative Commons licence, unless indicated otherwise in a credit line to the material. If material is not included in the article's Creative Commons licence and your intended use is not permitted by statutory regulation or exceeds the permitted use, you will need to obtain permission directly from the copyright holder. To view a copy of this licence, visit http://creativecommons.org/licenses/by/4.0/.

\section{References}

Alarcon, G. M., Bowling, N. A., \& Khazon, S. (2013). Great expectations: A meta-analytic examination of optimism and hope. Personality and Individual Differences, 54(7), 821-827. https://doi.org/10.1016/j. paid.2012.12.004

Aspinwall, L. G., Richter, L., \& Hoffman, R. R. (2001). Understanding how optimism works: An examination of optimists' adaptive moderation of belief and behavior. In E. C. Chang (Ed.), Optimism \& pessimism: Implications for theory, research, and practice (pp. 217-238). Washington, DC, US: American Psychological Association.

Asparouhov, T., \& Muthén, B. (2014). Auxiliary variables in mixture modeling: Three-step approaches using Mplus. Structural Equation Modeling: A Multidisciplinary Journal, 21(3), 329-341. https://doi. org/10.1080/10705511.2014.915181

Barnett, M. D., \& Martinez, B. (2015). Optimists: It could have been worse; Pessimists: It could have been better. Dispositional optimism and pessimism and counterfactual thinking. Personality and Individual Differences, 86, 122-125. https://doi.org/10.1016/j.paid.2015.06.010

Baumeister, R. F., Vohs, K. D., \& Oettingen, G. (2016). Pragmatic prospection: How and why people think about the future. Review of General Psychology, 20, 3-16. https://doi.org/10.1037/gpr0000060

Blasco-Belled, A., Rogoza, R., Torrelles-Nadal, C., \& Alsinet, C. (2020). Emotional intelligence structure and its relationship with life satisfaction and happiness: New findings from the bifactor model. Journal of Happiness Studies, 21, 2031-2049. https://doi.org/10.1007/s10902-019-00167-X

Boman, P., \& Yates, G. C. (2001). Optimism, hostility, and adjustment in the first year of high school. The British Journal of Educational Psychology, 71(3), 401-411. https://doi.org/10.1348/000709901158587 
Bouchard, L., Carver, C., Mens, M., \& Scheier, M. (2017). Optimism, health, and well-being. In D. S. Dunn (Ed.), Positive Psychology: Established and Emerging Issues (Routledge, pp. 112-130).

Bradburn, N. M. (1969). The Structure of Psychological Well-Being. Chicago, IL: Aldine Publishing Company. https://doi.org/10.1037/t10756-000.

Carver, C. S., Lehman, J. M., \& Antoni, M. H. (2003). Dispositional pessimism predicts illness-related disruption of social and recreational activities among breast cancer patients. Journal of Personality and Social Psychology, 84(4), 813-821. https://doi.org/10.1037/0022-3514.84.4.813

Carver, C. S., \& Scheier, M. (1998). On the self-regulation of behavior. Cambridge University Press.

Carver, C. S., Scheier, M. F., \& Segerstrom, S. C. (2010). Optimism. Clinical Psychology Review, 30(7), 879-889. https://doi.org/10.1016/j.cpr.2010.01.006

Chang, E. C., Yi, S., Liu, J., Kamble, S. V., Zhang, Y., Shi, B., Ye, Y., Fang, Y., Cheng, K., Xu, J., Shen, J., Li, M., \& Chang, O. D. (2020). Coping behaviors as predictors of hedonic well-being in Asian Indians: Does being optimistic still make a difference? Journal of Happiness Studies, 21(1), 289-304. https:// doi.org/10.1007/s10902-019-00087-w

Conversano, C., Rotondo, A., Lensi, E., Della Vista, O., Arpone, F., \& Reda, M. A. (2010). Optimism and its impact on mental and physical well-being. Clinical Practice and Epidemiology in Mental Health, 6 , 25-29. https://doi.org/10.2174/1745017901006010025

Coyne, J. C., \& Racioppo, M. W. (2000). Never the twain shall meet? Closing the gap between coping research and clinical intervention research. American Psychologist, 55(6), 655-664. https://doi.org/10. 1037/0003-066X.55.6.655

Creed, P. A., Patton, W., \& Bartrum, D. (2002). Multidimensional properties of the LOT-R: Effects of optimism and pessimism on career and well-being related variables in adolescents. Journal of Career Assessment, 10(1), 42-61. https://doi.org/10.1177/1069072702010001003

Daukantaitè, D., \& Zukauskiene, R. (2012). Optimism and subjective well-being: affectivity plays a secondary role in the relationship between optimism and global life satisfaction in the middle-aged women longitudinal and cross-cultural findings. Journal of Happiness Studies, 13(1), 1-16. https:// doi.org/10.1007/s10902-010-9246-2

Deptula, D. P., Banks, G. G., Barnes, S. E., \& Cohen, R. (2021). A person-centered analysis of change in children's peer optimism and its relation to peer social competence. Journal of Happiness Studies, 22, 1217-1238. https://doi.org/10.1007/s10902-020-00270-4

Diener, E., Emmons, R. A., Sem, R. J. L., \& Griffin, S. (1985). The satisfaction with life scale. Journal of Personality Assessment, 49.

Diener, E., Suh, E. M., Lucas, R. E., \& Smith, H. L. (1999). Subjective weil-being: Three decades of progress. Psychological Bulletin, 125(2), 276-302.

Eagleson, C., Hayes, S., Mathews, A., Perman, G., \& Hirsch, C. R. (2016). The power of positive thinking: Pathological worry is reduced by thought replacement in Generalized Anxiety Disorder. Behaviour Research and Therapy, 78, 13-18. https://doi.org/10.1016/j.brat.2015.12.017

Eichner, K. V., Kwon, P., \& Marcus, D. K. (2014). Optimists or optimistic? A taxometric study of optimism. Psychological Assessment, 26(3), 1056-1061. https://doi.org/10.1037/pas0000010.

Extremera, N., Durán, A., \& Rey, L. (2007). Perceived emotional intelligence and dispositional optimism-pessimism: Analyzing their role in predicting psychological adjustment among adolescents. Personality and Individual Differences, 42, 1069-1079. https://doi.org/10.1016/j.paid.2006.09.014

Extremera, N., \& Fernández-Berrocal, P. (2014). The subjective happiness scale: translation and preliminary psychometric evaluation of a spanish version. Social Indicators Research, 119(1), 473-481. https://doi.org/10.1007/s11205-013-0497-2

Ferrando, P. J., Chico, E., \& Tous, J. M. (2002). Propiedades psicométricas del test de optimismo Life Orientation Test. Psicothema, 14(3), 673-680.

Fredrickson, B. (2001). The role of positive emotions in positive psychology. The broaden-and-build theory of positive emotions. The American Psychologist, 56(3), 218-226. https://doi.org/10.1037/ 0003-066X.56.3.218

Gallagher, M. W., Long, L. J., Richardson, A., \& Souza, J. M. D. (2019). Resilience and coping in cancer survivors: the unique effects of optimism and mastery. Cognitive Therapy and Research, 43(1), 32-44. https://doi.org/10.1007/s10608-018-9975-9

Glaesmer, H., Rief, W., Martin, A., Mewes, R., Brähler, E., Zenger, M., \& Hinz, A. (2012). Psychometric properties and population-based norms of the Life Orientation Test Revised (LOT-R). British Journal of Health Psychology, 17(2), 432-445. https://doi.org/10.1111/j.2044-8287.2011.02046.x

Herzberg, P. Y., Glaesmer, H., \& Hoyer, J. (2006). Separating optimism and pessimism: A robust psychometric analysis of the revised Life Orientation Test (LOT-R). Psychological Assessment, 18(4), 433-438. https://doi.org/10.1037/1040-3590.18.4.433 
Hinz, A., Sander, C., Glaesmer, H., Brähler, E., Zenger, M., Hilbert, A., \& Kocalevent, R. D. (2017). Optimism and pessimism in the general population: Psychometric properties of the Life Orientation Test (LOT-R). International Journal of Clinical and Health Psychology, 17(2), 161-170. https:// doi.org/10.1016/j.ijchp.2017.02.003

Joshanloo, M., Park, Y. O., \& Park, S. H. (2017). Optimism as the moderator of the relationship between fragility of happiness beliefs and experienced happiness. Personality and Individual Differences, 106, 61-63. https://doi.org/10.1016/j.paid.2016.10.039

Jovanović, V., \& Gavrilov-Jerković, V. (2013). Dimensionality and validity of the serbian version of the life orientation test-revised in a sample of youths. Journal of Happiness Studies, 14(3), 771-782. https://doi.org/10.1007/s10902-012-9354-2

Jovanović, V., Molenaar, D., Gavrilov-Jerković, V., \& Lazić, M. (2021). Positive expectancies and subjective well-being: A prospective study among undergraduates in Serbia. Journal of Happiness Studies, 22(3), 1239-1258. https://doi.org/10.1007/s10902-020-00271-3

Kline, R. (2013). Applied quantitative analysis in education and the social sciences. In Y. Petscher \& C. Schatschneider (Eds.) (pp. 171-207). New York: Routledge.

Koydemir, S., Sökmez, A. B., \& Schütz, A. (2020). A Meta-Analysis of the Effectiveness of Randomized Controlled Positive Psychological Interventions on Subjective and Psychological Well-Being. Applied Research in Quality of Life, 1-41. https://doi.org/10.1007/s11482-019-09788-Z

Li, W.-D., Li, S., Fay, D., \& Frese, M. (2019). Reciprocal relationships between dispositional optimism and work experiences: A five-wave longitudinal investigation. Journal of Applied Psychology. https://doi.org/10.1037/ap10000417

Litt, M. D., Tennen, H., Affleck, G., \& Klock, S. (1992). Coping and cognitive factors in adaptation to in vitro fertilization failure. Journal of Behavioral Medicine, 15(2), 171-187. https://doi.org/10. 1007/BF00848324

Lubke, G. H., \& Muthén, B. (2005). Investigating population heterogeneity with factor mixture models. Psychological Methods, 10(1), 21. https://doi.org/10.1037/1082-989X.10.1.21.

Lyubomirsky, S., \& Lepper, H. S. (1999). A measure of subjective happiness: Preliminary reliability and construct validation. Social Indicators Research. https://doi.org/10.1023/A:1006824100041

Marshall, G. N., Wortman, C. B., Kusulas, J. W., Hervig, L. K., \& Vickers, R. R. (1992). Distinguishing optimism from pessimism: relations to fundamental dimensions of mood and personality. Journal of Personality and Social Psychology, 62(6), 1067-1074. https://doi.org/10.1037/0022-3514.62.6. 1067

Morin, A. J. S., Boudrias, J. S., Marsh, H. W., McInerney, D. M., Dagenais-Desmarais, V., Madore, I., \& Litalien, D. (2017). Complementary variable- and person-centered approaches to the dimensionality of psychometric constructs: Application to psychological wellbeing at work. Journal of Business and Psychology, 32(4), 395-419. https://doi.org/10.1007/s10869-016-9448-7

Muthén, L.K. and Muthén, B.O. (1998-2012). Mplus User's Guide. 7th Edition. Los Angeles, CA: Muthén \& Muthén.

Muthén, B. O., \& Muthén, L. K. (2000). Integrating person-centered and variable-centered analyses: Growth mixture modeling with latent trajectory classes. Alcoholism: Clinical and Experimental Research. https://doi.org/10.1111/j.1530-0277.2000.tb02070.x

Nakano, K. (2004). Psychometric properties of the life orientation test-revised in samples of Japanese students. Psychological Reports, 94(3I), 849-855. https://doi.org/10.2466/pr0.94.3.849-855

Nes, L. S., \& Segerstrom, S. C. (2006). Dispositional optimism and coping: A meta-analytic review. Personality and Social Psychology Review, 10(3), 235-251. https://doi.org/10.1207/s15327957pspr1003_3

Nylund, K. L., Asparouhov, T., \& Muthén, B. O. (2007). Deciding on the number of classes in latent class analysis and growth mixture modeling: A Monte Carlo simulation study. Structural Equation Modeling, 14(4), 535-569. https://doi.org/10.1080/10705510701575396.

Prati, G., \& Pietrantoni, L. (2009). Optimism, social support, and coping strategies as factors contributing to posttraumatic growth: A meta-analysis. Journal of Loss and Trauma, 14(5), 364-388. https://doi.org/ $10.1080 / 15325020902724271$

Rey, L., \& Extremera, N. (2014). Positive psychological characteristics and interpersonal forgiveness: Identifying the unique contribution of emotional intelligence abilities, Big Five traits, gratitude and optimism. Personality and Individual Differences. https://doi.org/10.1016/j.paid.2014.04.030

Sánchez-Álvarez, N., Extremera, N., \& Fernández-Berrocal, P. (2016). The relation between emotional intelligence and subjective well-being: A meta-analytic investigation. Journal of Positive Psychology, 11(3), 276-285. https://doi.org/10.1080/17439760.2015.1058968

Scheier, M. F., \& Carver, C. (1985). Optimism, coping, and health: Assessment and implications of generalized outcome expectancies. Health Psychology, 4(3), 219-247. https://doi.org/10.1037/0278-6133.4.3. 219 
Scheier, M. F., Carver, C. S., \& Bridges, M. W. (1994). Distinguishing optimism from neuroticism (and trait anxiety, self-mastery, and self-esteem): A reevaluation of the Life Orientation Test. Journal of Personality and Social Psychology, 67(6), 1063-1078. https://doi.org/10.1037/0022-3514.67.6.1063

Segerstrom, S. C., Carver, C. S., \& Scheier, M. F. (2017). Optimism. In The Happy Mind: Cognitive Contributions to Well-Being (pp 195-212). Springer International Publishing.

Shapira, L. B., \& Mongrain, M. (2010). The benefits of self-compassion and optimism exercises for individuals vulnerable to depression. Journal of Positive Psychology, 5(5), 377-389. https://doi.org/10.1080/ 17439760.2010 .516763

Salovey, P., \& Mayer, J. D. (1990). Emotional intelligence. Imagination, Cognition and Personality, 9(3), 185-211. https://doi.org/10.2190/DUGG-P24E-52WK-6CDG.

Salovey, P., Mayer, J., Goldman, S., Turvey, C., \& Palfai, T. (1995). Emotional attention, clarity, and repair: Exploring emotional intelligence using the trait meta-mood scale. In Pennebaker J. (Ed.), APA Science volume series (pp. 125-154). Washington, DC: American Psychological Association.

Szczygieł, D., \& Mikolajczak, M. (2017). Why are people high in emotional intelligence happier? They make the most of their positive emotions. Personality and Individual Differences, 117, 177-181. https://doi.org/10.1016/j.paid.2017.05.051

Taylor, S. E., \& Schneider, S. K. (1989). Coping and the simulation of events. Social Cognition, 7(2), 174194. https://doi.org/10.1521/soco.1989.7.2.174

Tejada-Gallardo, C., Blasco-Belled, A., Torrelles-Nadal, C., \& Alsinet, C. (2020). How does emotional intelligence predict happiness, optimism, and pessimism in adolescence? Investigating the relationship from the bifactor model. Current Psychology. https://doi.org/10.1007/s12144-020-01061-z

van der Velden, P. G., Kleber, R. J., Fournier, M., Grievink, L., Drogendijk, A., \& Gersons, B. P. R. (2007). The association between dispositional optimism and mental health problems among disaster victims and a comparison group: A prospective study. Journal of Affective Disorders, 102(1-3), 35-45. https:// doi.org/10.1016/J.JAD.2006.12.004

Vázquez, C., Duque, A., \& Hervás, G. (2013). Satisfaction with life scale in a representative sample of spanish adults: Validation and normative data. Spanish Journal of Psychology, 16(e82), 1-15. https://doi. org/10.1017/sjp.2013.82

von Eye, A., \& Bogat, G. A. (2006). Person-oriented and variable-oriented research: concepts, results, and development. Merrill-Palmer Quarterly, 52(3), 390-420. https://doi.org/10.2307/23096201

Wetzel, E., Leckelt, M., Gerlach, T. M., \& Back, M. D. (2016). Distinguishing subgroups of narcissists with latent class analysis. European Journal of Personality, 30(4), 374-389. https://doi.org/10.1002/ per.2062.

Wright, J. H., Brown, G. K., Thase, M. E., \& Basco, M. R. (2006). Learning cognitive-behavior therapy: an illustrated guide. American Psychuatric Association.

Wrzus, C., \& Roberts, B. W. (2017). Processes of personality development in adulthood: The TESSERA Framework. Personality and Social Psychology Review, 21(3), 253-277. https://doi.org/10.1177/10888 68316652279

Publisher's Note Springer Nature remains neutral with regard to jurisdictional claims in published maps and institutional affiliations.

\section{Authors and Affiliations}

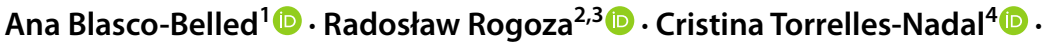 Carles Alsinet ${ }^{4}$ (I)}

Radosław Rogoza

r.rogoza@uksw.edu.pl

Cristina Torrelles-Nadal

cristina.torrelles@udl.cat

Carles Alsinet

carles.alsinet@udl.cat

1 Universitat de Girona, Pujada de Sant Domènec, 9, 17004 Girona, Spain 
2 Cardinal Stefan Wyszyński University in Warsaw, Dewajtis 5, 01-815 Warszawa, Poland

3 Social Innovation Chair, University of Lleida, Avinguda de l'estudi general 4, 25001 Lleida, Spain

4 Universitat de Lleida, Avinguda de l'estudi general n4, 25001 Lleida, Spain 